\title{
TTR
}

Traduction, terminologie, re?daction

\section{Hans J. Vermeer (1996). A skopos Theory of Translation (Some Arguments for and against). Heidelberg, TEXTconTEXT (Band 1)}

\section{Nadja Grbić et Michaela Wolf}

Volume 12, numéro 2, 2e semestre 1999

Poésie, cognition, traduction II - Autour d'un poème de W. H. Auden

Poetry, Cognition, Translation II — On a Poem by W. H. Auden

URI : https://id.erudit.org/iderudit/037381ar

DOI : https://doi.org/10.7202/037381ar

Aller au sommaire du numéro

Éditeur(s)

Association canadienne de traductologie

ISSN

0835-8443 (imprimé)

1708-2188 (numérique)

Découvrir la revue

Citer ce compte rendu

Grbić, N. \& Wolf, M. (1999). Compte rendu de [Hans J. Vermeer (1996). A skopos

Theory of Translation (Some Arguments for and against) . Heidelberg,

TEXTconTEXT (Band 1)]. TTR, 12(2), 196-197. https://doi.org/10.7202/037381ar

Tous droits réservés ( TTR: traduction, terminologie, rédaction — Les auteurs, Ce document est protégé par la loi sur le droit d’auteur. L’utilisation des d'utilisation que vous pouvez consulter en ligne.

https://apropos.erudit.org/fr/usagers/politique-dutilisation/ 
La collection Wissenschaft (Science) apparue en 1996 chez l'éditeur TEXTconTEXT se propose de publier des monographies traductologiques ainsi que des recueils qui traitent de la traduction comme " activité culturelle " au sens le plus large du terme. Le directeur de la collection se concentre sur la perspective holistique de la traduction et de l'interprétariat et privilégie leurs aspects fonctionnels. Dans le texte qui suit, nous livrons un compte rendu des quatre premiers volumes de cette collection.'

\section{Hans J. Vermeer (1996). A skopos Theory of Translation (Some Arguments for and against). Heidelberg, TEXTconTEXT (Band 1)}

Dans son étude, Vermeer suit d'abord le modèle théorique classique : énoncé de la terminologie, puis thèse-antithèse. Après l'explication de notions clés, est présentée la terminologie spécifique du skopos, qui se réalise dans l'acte de la traduction. S'appuyant sur ces instruments terminologiques et méthodologiques, la théorie du skopos est exposée dans le détail.

Dans le chapitre suivant, Vermeer aborde les thèses centrales de la théorie du skopos tout en mettant l'accent sur la portée générale de cette théorie. Dans la partie de synthèse, il réunit les objections les plus importantes contre la théorie du skopos. Dans la discussion concernant le rôle du texte source au sein du processus de traduction,

\footnotetext{
1 Nous remercions Klaus Ertler pour la traduction du texte et Jean-Marc Gouanvic pour sa relecture attentive.
} 
Vermeer répond longuement à la théorie selon laquelle le skopos ne serait pas applicable à la traduction littéraire, puisque le texte source en tant que partie de la culture source devrait être traduit dans le sens de celle-ci, donc d'une façon " fidèle " (p. 37). Son argument principal contre une telle réduction est le suivant : aucun texte ne possède une signification stable et toute méthode est individuelle. Par conséquent, il s'inscrit dans la méthodologie postmoderne de la théorie de la traduction. Ensuite, Vermeer discute les relations entre la théorie du skopos et les autres conceptualisations courantes de la traductologie, comme la Relevance Theory selon Sperber et Wilson (1986) et Gutt (1991, pp. 51-68; réédité et étendu en $2000 \mathrm{chez}$ St. Jerome Publishing). Il les applique au principe de l'agir traductologique conçu par Holz-Mänttäri et à la théorie du skopos à laquelle il ajoute une nouvelle dimension. (Il est regrettable que, pour des raisons d'ordre éditorial, la Descriptive Translation Studies de Toury (1995) ne soit mentionnée que dans une note à la fin du texte.) Quant au principe de loyauté de Nord, Vermeer critique cette approche spécifiquement orientée vers la culture, qui doit être, selon lui, strictement séparée d'une théorie générale de la traduction. En fait, pour Vermeer, la culture n'a qu'un rôle secondaire. Selon lui, une théorie générale de la traduction doit être libre " from any (culture) specific conditions » (p. 22). Il semble oublier que la théorie ne peut exister sans la culture, car sa terminologie et sa méthodologie relèvent forcément d'une tradition, qui est, elle-même, intégrée dans la culture. L'abence remarquée de cette théorie du skopos dans le milieu anglophone peut être expliquée par le fait que, sauf exception, les publications de Vermeer n'existent qu'en langue allemande. Espérons que ce volume contribuera à combler ce manque. 